$\xi=$ 离

\title{
Natural products in green-detection of cancer cells, cancer therapy, and monitoring of therapeutic and cancer progression: A perspective
}

\author{
Muhammad Torequl Islam * \\ Department of Pharmacy, Southern University Bangladesh, Chittagong (Mehedibag)-4000, Bangladesh. \& Northeast Biotechnology Network \\ (RENORBIO), Postgraduate Program in Pharmaceutical Sciences, Federal University of Piauí, Teresina (Paiui)-64009-550, Brazil \\ *Corresponding author E-mail: rbiotufpi.br@gmail.com
}

\begin{abstract}
The natural products embedded with the molecular framework by combining with themselves or other molecules and biological micro/macro molecules. By the help of some special techniques, that can be incorporated to identify and detect different body markers as well as pathophysiological conditions. To date, a number of cancer detection methods are available. However, an early cancer detection is still remained the key problems, which causes delay, reduction of success rate in the cancer therapy, and increased the lethality, as cancer is a complicated and a large group of related diseases. To date, due to the promising biological compatibility and safety profile, many natural products have been used as anticancer drugs. Additionally, many of them are also included in the green syntheses, especially the plant-derived products. It is due their less or even non-toxic and economic character. This text offers a perspective on the detection of cancer by using natural products, along with a therapeutic and monitoring of treatment and cancer progression, suggests that, the natural products can be considered as leading tools in overall cancer management.
\end{abstract}

Keywords: Biomarkers; Chemical Compounds; Cancer Detection.

\section{Introduction}

Cancer, the general term usually describes a large group of related diseases. Our body is composed of trillions of cells. In a normal physiology all works together. At the beginning of cancer, one of them stops paying attention to the normal signals and/or may exert abnormal or altered functions and can tell cells to grow, stop growing or even to die. However, it shares almost the same needs and properties of normal cells, as it needs to survive and multiply in the same host, but becomes independent (Huda and Slone 1995; Segen and Wade 2002).

An early detection is one of the key problems in the treatment of cancer. Doubtless, cancer is detected in its later stages, and most often when it has compromised the function of one or more vital organ systems and is widespread throughout the body. Therefore, the early detection of cancer is of utmost importance in the proper diagnosis and treatment of each cancer, as the treatment plan is fully dependent on this fact. To date, a number detection method is available. However, no test is $100 \%$ accurate, as most of them according to their sensitivity and specificity result, false positive/false negative rates (Huda and Slone 1995; Segen and Wade 2002; Li et al. 2016).

Nowadays, the natural products (e.g. - plants, animals, microbes from terrestrial and marine environment origin) are being extensively used in many sectors, including food and beverages, cosmetics and toiletries, laboratory synthesis, treatment of diseases, and so on (Crotti et al. 2015; Islam et al. 2016). However, natural products can be used in the detection and diagnosis of diseases, especially the cancer (Chanda et al. 2011). This text offers a featuring hope, aiming to procure attention of the scientists to use natural products in the detection of cancer. Additionally, natural product-emphasized monitoring of therapeutic and cancer progression have been also depicted.

\section{Natural products in the detection of cancer cells}

Till date, a number of natural products have been marketed as anticancer drugs (Table 1).

Table 1: List of Natural Compounds Marketed for Anticancer Therapy

\begin{tabular}{lll}
\hline Sources & Lead compounds & Class \\
\hline \multirow{5}{*}{ Bacteria } & $\begin{array}{l}\text { Bleomycins } \\
\text { Dactinomycin } \\
\text { Daunobicin } \\
\text { Doxorubicin } \\
\text { Mitomycin } \\
\text { Mitoxantrone }\end{array}$ & \\
& Epothilones A-F & Antibiotics \\
& Vorinostat & Histone deacetylase inhibitors \\
Marine & Cytarabine & Marine products \\
& Trabectedin & Camptothecin analogs \\
& Camptothecin & Epipodophyllotoxins \\
& Etoposide & Taxanes \\
& Teniposide & Retinoids \\
& Paclitaxel & Vinca alkaloids \\
& Vinblastine & \\
\hline
\end{tabular}

In addition, there is an increasing interest arose in the production of semi-synthetic derivatives from natural active substances (lead 
compounds) to improve the biological activity or to reduce the side effects. Examples of some marketed semi-synthetic anticancer drugs are: cabazitel, docetaxel, epirubicin, idarubicin, irinotecan, ixabepilones, nab-paclitaxel, topotecan, tretinoin, vindesine, vinflunine and vinorelbine. However, natural products can be used in the detection of cancer (Chanda et al. 2011).

The mammalian sialic acid N-glycolylneuraminic acid is metabolically incorporated from the dietary sources (e.g. - red meat and milk) into fetuses and some normal tissues. However, it is highly found in glycoproteins and glycolipids of human tumors. Thus, these kinds of cancer cells can be detected through the detection of N-glycolylneuraminic acid by using the immunohistochemical, enzyme-linked immunosorbent assay (ELISA), Western blot and flow cytometry analyses as well as affinity chromatography (Diaz et al. 2009).

Withaferin A, a steroidal lactone isolated from Withania somnifera is evident to target heat shock protein 90 (Hsp90) in human pancreatic (Panc-1) cancer cells (Yu et al. 2010). On the other hand, the nano system comprising of silica using biocompounds extracted from the Mexican tree "Palo azul" (Eysenhardtia polystachya) are evident to incorporate into human breast cancer (MCF-7) cells (Ferreira et al. 2015). The conjugate compound of 2-aminoethyl diphenyl borateand 5,3',4'tridemethylnobiletin (a unique polymethoxy flavone metabolite derived from citrus polymethoxy flavone) can be used to detect different biological samples, including floating cells, adherent cells, and animal tissues (Chen et al. 2015).

The bioaffinity technique, cell membrane chromatography is a widely used method for characterizing the interactions between drugs and membrane receptors, especially for complex samples such as herbal medicines. Baicalein, wogonin, chrysin, oroxylin A, neobaicalein and rivularin from Radix scutellariae were found to retain in human liver cancer (HepG2) cells (Jia et al. 2016) Moreover, the anthracyclines produced by actinobacteria are used effectively in the treatment of cancer, can be detected their levels in biological samples by using spectroscopic methods such as mass spectrometry. It should be mentioned that, the anthracyclines are toxic to their producers (Bauermeister et al. 2016). Thus, the detection of these drugs may be an application of controlling and monitoring the levels of anticancer drugs in surrounding normal cells.

Transferrin receptor is highly expressed in tumor cells. In a study, the binding capability of some phenolic compounds (twenty-five flavonol glycosides and eight phenolic acids) from the flowers of Bauhinia blakeana was detected by using HPLC-diode-array detector-multi-stage mass spectrometry-transferrin-fluorescence detector method (Liu et al. 2016). There is no doubt that, the breast cancer is one of the most lethal types of cancer in women worldwide due to the late stage detection and resistance to traditional chemotherapy. The human epidermal growth factor receptor 2 (HER2) is considered as a validated target in breast cancer therapy. The bioinformatics tools can be used to identify the novel effective HER2 inhibitors as well as monitor their efficacy. The structure-based virtual screening combined with the absorption, distribution, metabolism, excretion and toxicity is capable to monitor in this case. In a recent study, by using this tool, $\mathrm{Li}$ et al (2016) found ZINC15122021 (a natural compound) to inhibit the kinase activity against HER2 as well as presenting an outstanding cell proliferation inhibition activity against both SKBR3 and BT474 cell lines. Furthermore, streptavidin-magnetic nano-bead was demonstrated to detect the adenosine content in normal human urines and cancer patient urines, suggesting a reliable and sensitive adenosine detection method in the early clinical diagnosis and medical research (Feng et al. 2016).

The cone beam computed tomography as well as fluoroscopy can be used to detect the lipiodol (ethiodized oil, is a poppy seed oil used for cancer imaging) retention pattern in human hepatocellular carcinoma (HCC) cells (Hu et al. 2016). In a recent study, the natural product 4'-geranyloxyferulic acid and its conjugate with 1nitroarginine methyl ester were found to detect in mononuclear cells by applying the high-performance liquid chromatography (HPLC) technique (Taddeo et al. 2017).

Many synthetic substances such as hydrazine and sodium borohydride are used as powerful reducing agents in the synthesis of metallic nano-particles (Esumi et al. 2001). However, these reducing agents are highly toxic to the living organisms and to the ecosystem. On the other hand, the herbs and plants are the potential sources of antioxidants (Hoyoku et al., 2007). The uses of such kind of antioxidants in the diets and as medicaments are widely known to be non-toxic to the living organisms and to the environment (Holst and Williamson 2008). Recently, a number of phytochemicals have been employed for green 'nano-synthesis'; phytochemicals from soy, tea and cumin are some of the examples of them (Shukla et al. 2008; Katti et al. 2009; Nune et al. 2009). Chanda et al (2011) prepared cinnamon-coated gold nanoparticles (average diameter of $13 \pm 5 \mathrm{~nm}$ ) that had been internalized in normal human prostate (PC-3) and MCF-7, and prostate cancer (PC-3) cells. They observed that, the non-toxic cinnamonphytochemical-coated gold nano-particles produced an excellent detectable photoacoustic signals from the internalized cancer cells than the normal PC-3 cells (Figure 1). Interestingly, the phytochemical-coated-nano-particles did not affect the relative cell viability in any cases.
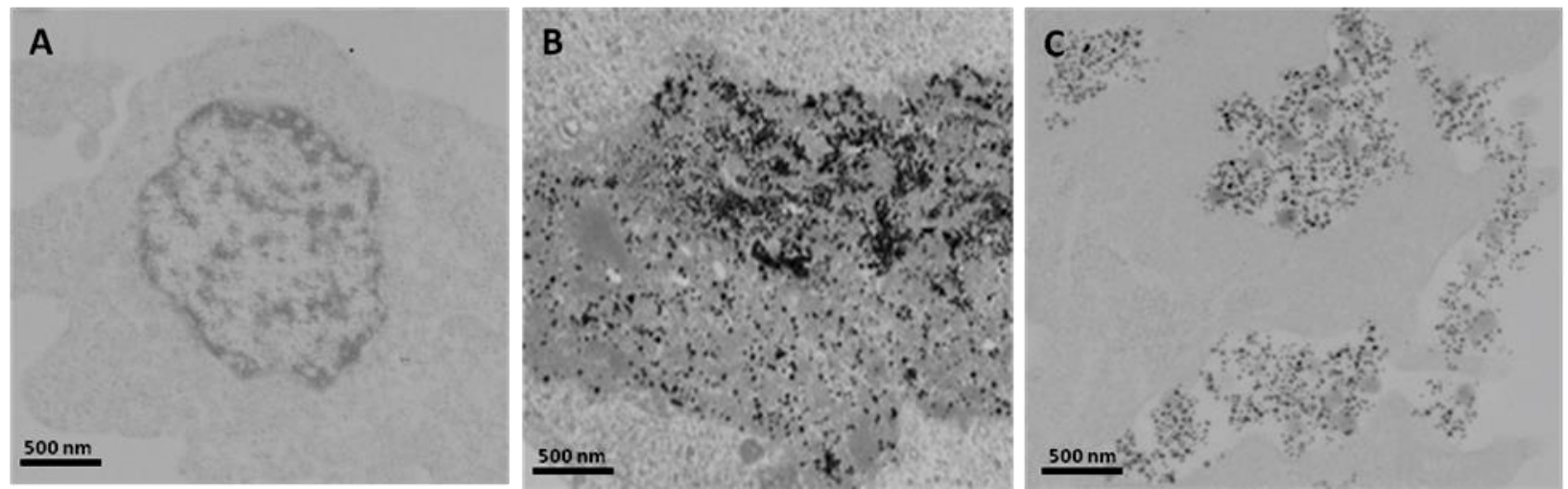

Fig. 1: Transmission Electron Microscopy Images Showing (A) Normal PC-3 (B) MCF-7 and (C) PC-3 Cells Internalizations of CinnamonPhytochemical-Coated Gold Nano-Particles. (Source: Chanda et al. 2011)

It should be mentioned that, the phytochemical constituents of cinnamon include: essential oils (1-4\%), polyphenols $(5-10 \%)$, carbohydrates (80-90\%), and others such as gum, mucilage, resin and calcium monoterpenes oxalate. Among the essential oils, cinnamon contains aldehydes up to $60-80 \%$, including transcinnamaldehyde (Mathew and Abraham 2006; Lopez et al. 2007;
Shan et al. 2007). It seems, natural products of various chemical classes can be used in 'GREEN SYNTHESIS' as well as cancer cell detection. Moreover, natural products can be used to target genetic materials and can be monitored their activities there. For an example, the purine nucleoside phosphorylase activity is involved in cell survival and function. HPLC method can be used 
for the determination of purine nucleoside phosphorylase activity in plasma (Giuliani et al. 2016).

\section{Relevant perspectives}

Natural products and their advanced preparations can be used not only for the treatment, but also monitoring the anticancer activity. For an example, catechin nanoemulsion (composition: catechin extract, lecithin, Tween 80 , and deionized water; mean particle size: $11.45 \mathrm{~nm}$ ) mediated inhibitory effect of human PC-3 cells was detected by using high-performance liquid chromatographymass spectrometry method (Tsai and Chen 2016). In a recent study, celastrol (a quinonemethidetriterpene an abundant bioactive constituent of Tripterygium wilfordii) was used to detect RNA replication and protein synthesis of DENV via specific microRNA silencing and inhibition (Yu et al. 2017).

On the other hand, (-)-epigallocatechin-3-O-gallatenanoethosomes (composition: $0.2 \%$ EGCG, 2\% soybean phosphatidylcholine, $30 \%$ ethanol, $1 \%$ Tween- 80 and $0.1 \%$ sugar esters) were investigated as a preventative treatment for human melanoma (A-375) cells, where the transdermal delivery of the nanopreparation was used to monitor the tumor growth (Liao et al. 2016). In another study, Capistrano et al (2016) demonstrated that, Gloriosa superba extracts $(0.3-3.0 \mathrm{mg} / \mathrm{kg})$ rich in colchicines and colchicoside prepared as a putative pro-drug, when administered in pancreatic tumor (PANC02)-bearing C57BL/6 mice for 10 successive days, significantly reduced the Ki-67 scores and relative tumor volumes. In this study, positron emission tomography imaging using 2-deoxy-2-[ $\left.{ }^{18} \mathrm{~F}\right]$ fluoro-d-glucose $\left({ }^{18} \mathrm{~F}\right.$ FDG) was used to detect the in vivo $G$. superba extracts uptake profile and overall cancer progression. Moreover, artesumycin, a fluorescent hybrid of the natural products marmycin A and artemisinin was found to inhibit the cancer cell proliferation through an iron-dependent manner, which was visually detected by using fluorescence microscopy (Mariani et al. 2016).

As a cancer treatment strategy, in many cases, surgery is followed by the radiotherapy. However, the radiotherapy exerts a number of complications, including cancer treatment mediated a secondary cancer. Borda Rodríguez and AnduezaIriarte (2016) suggested that rosehip oil can be used to prevent epithelitis in the patients with head and neck cancer treated by intensity modulated radiotherapy. Vaccines, the biological preparations are designed to promote tumor specific immune responses. However, other cancer treatment strategies such as surgery and ablation, chemotherapy, and radiotherapy, can also induce antitumor immunity, thereby having cancer vaccine effects. In this regard, the monitoring of patients' immune responses at the baseline and after standard of care treatment is shedding light on immune biomarkers (Butterfield et al. 2015). Photodynamic therapy can be used in the management of various cancers. However, the sensitivity towards light of any natural product should be considered, as photoinduced alteration of the substance, especially the plant-derived drugs can induce cell death via different mechanisms, including apoptosis, necrosis, autophagy, cell cycle regulation and even the regulation of various cell signaling pathways (George and Abrahamse 2016).

Doubtless, the anticancer drug-induced toxicities and the management are two burning questions. Therefore, after administration, the drug concentrations need to maintain in an appropriate range to be effective. Furthermore, the drug dosage defined during the clinical studies may be inappropriate for the individual patient due to differences in drug absorption, metabolism and excretion profiles. Thus, the therapeutic drug monitoring is an important challenge in cancer chemotherapy. According to Crotti et al (2015) mass spectrometry-based methods can be used for pharmacokinetic quantification of anticancer drugs in biological samples, especially those are derived from natural origin. Moreover, Khoogar et al (2016) also demonstrated that, the natural products are capable to reduce off-target toxicity of therapeutics with the continuation of on-targeting the cancer cells.

\section{Conclusion}

The application of natural products is immense and charismatic. From the accumulated evidences, this text says that, the natural products can be applied for the detection of cancer cells along with the treatment, and monitoring of the cancer therapy as well as cancer progression. However, more researches are necessary concerning to the toxicological effects on normal cells in each application. In fact, each natural product has a number of pharmacological effects on its producers as well as towards other biological systems.

\section{Conflict of interest}

None declared.

\section{References}

[1] Huda W, Slone R. Review of Radiologic Physics. Lippincott Williams \& Wilkins: Philadelphia, 1995.

[2] Segen JC, Wade J. The Patient's Guide to Medical Tests. Infobase Publishing, 2002

[3] Li J, Wang H, Li J, Bao J, Wu C. Discovery of a Potential HER2 Inhibitor from Natural Products for the Treatment of HER2Positive Breast Cancer. Int J Mol Sci 2016; 17(7). https://doi.org/10.3390/ijms17071055.

[4] Crotti S, Posocco B, Marangon E, Nitti D, Toffoli G, Agostini M. Mass spectrometry in the pharmacokinetic studies of anticancer natural products. Mass Spectrom Rev 2015. https://doi.org/10.1002/mas.21478.

[5] Islam MT, Mata AMOF, Aguiar RPS, Paz MFCJ, Alencar MVOB, Melo-Cavalcante AAC. Therapeutic Potential of Essential Oils Focusing on Diterpens. Phytother Res 2016; 30(9):1420-1444. https://doi.org/10.1002/ptr.5652.

[6] Chanda N, Shukla R, Zambre A, Mekapothula S, Kulkarni RR, Katti K, Bhattacharyya K, Fent GM, Casteel SW, Boote EJ, Viator JA, Upendran A, Kannan R, Katti KV. An Effective Strategy for the Synthesis of Biocompatible Gold Nanoparticles Using Cinnamon Phytochemicals for Phantom CT Imaging and Photoacoustic Detection of Cancerous Cells. Pharm Res 2011; 28:279-291. https://doi.org/10.1007/s11095-010-0276-6.

[7] Diaz SL, Padler-Karavani V, Ghaderi D, Hurtado-Ziola N, Yu H, Chen X, Brinkman-Van der Linden ECM, Varki A, Varki NM. Sensitive and Specific Detection of the Non-Human Sialic Acid $N$ Glycolylneuraminic Acid in Human Tissues and Biotherapeutic Products. PLoS ONE 2009; 4(1):e4241. https://doi.org/10.1371/journal.pone.0004241.

[8] Yu JS, Tseng CK, Lin CK, Hsu YC, Wu YH, Hsieh CL, Lee JC. Celastrol inhibits dengue virus replication via up-regulating type I interferon and downstream interferon-stimulated responses. Antiviral Res 2017 ; 137:49-57. https://doi.org/10.1016/j.antiviral.2016.11.010.

[9] Ferreira G, Hernandez-Martinez AR, Pool H, Molina G, Cruz-Soto M, Luna-Barcenas G, Estevez M. Synthesis and functionalization of silica-based nanoparticles with fluorescent biocompounds extracted from Eysenhardtia polystachya for biological applications Mater Sci Eng C Mater Biol Appl 2015; 57:49-57. https://doi.org/10.1016/j.msec.2015.07.012.

[10] Chen J, Song M, Wu X, Zheng J, He L, McClements DJ, Decker E, Xiao H. Direct Fluorescent Detection of a Polymethoxyflavone in Cell Culture and Mouse Tissue. J Agric Food Chem 2015; 63(49):10620-10627. https://doi.org/10.1021/acs.jafc.5b04484.

[11] Jia D, Chen X, Cao Y, Wu X, Ding X, Zhang H, Zhang C, Chai Y, Zhu Z. On-line comprehensive two-dimensional HepG2 cell membrane chromatographic analysis system for charactering antihepatoma components from rat serum after oral administration of Radix scutellariae: A strategy for rapid screening active compounds in vivo. J Pharm Biomed Anal 2016; 118:27-33. https://doi.org/10.1016/j.jpba.2015.10.013.

[12] Bauermeister A, Zucchi TD, Moraes LA. Mass spectrometric approaches for the identification of anthracycline analogs produced by actinobacteria. J Mass Spectrom 2016; 51(6):437-445. https://doi.org/10.1002/jms.3772.

[13] Mariani A, Mai TT, Zacharioudakis E, Hienzsch A, Bartoli A Cañeque T, Rodriguez R. Iron-dependent lysosomal dysfunction 
mediated by a natural product hybrid. ChemCommun (Camb) 2016; 52(7):1358-1360. https://doi.org/10.1039/C5CC09255H.

[14] Feng C, Hou Z, Jiang W, Sang L, Wang L. Binding induced colocalization activated hybridization chain reaction on the surface of magnetic nanobead for sensitive detection of adenosine. Biosens
Bioelectron
2016
$86: 966-970$ https://doi.org/10.1016/j.bios.2016.07.108.

[15] Hu J, Maybody M, Cao G, Wang X, Chen H, Zhu X, Yang R, Wang X. Lipiodol retention pattern assessed by cone beam computed tomography during conventional transarterial chemoembolization of hepatocellular carcinoma: accuracy and correlation with response. Cancer Imaging 2016; 16(1):32 https://doi.org/10.1186/s40644-016-0090-4.

[16] Taddeo VA, Genovese S, Carlucci G, Ferrone V, Patruno A, Ferrone A, de Medina P, Fiorito S, Epifano F. Quantitative profiling of 4'-geranyloxyferulic acid and its conjugate with 1-nitroarginine methyl ester in mononuclear cells by high-performance liquid chromatography with fluorescence detection. J Pharm Biomed Anal 2017; 133:49-55. https://doi.org/10.1016/j.jpba.2016.11.016.

[17] Esumi K, Kameo A, Suzuki A, Torigoe K. Preparation of gold nanoparticles in formamide and N, N-dimethylformamide in the presence of poly(amidoamine) dendrimers with surface methyl ester groups. Colloids Surf, a Physicochem Eng Asp 2001; 189:155-161. https://doi.org/10.1016/S0927-7757(00)00811-6.

[18] Hoyoku N, Yoshiko S, Harukuni T, Mitsuharu M. Cancer control by phytochemicals. Curr Pharm Des 2007; 13:3394-3399. https://doi.org/10.2174/138161207782360519.

[19] Holst B, Williamson G. Nutrients and phytochemicals: from bioavailability to bioefficacy beyond antioxidants. CurrOpinBiotechnol 2008; 19:73-82. https://doi.org/10.1016/j.copbio.2008.03.003.

[20] Shukla R, Nune SK, Chanda N, Katti K, Mekapothula S, Kulkarni RR, Welshons WV, Kannan R, Katti KV. Soybeans as a phytochemical reservoir for the production and stabilization of biocompatible gold nanoparticles. Small 2008; 4(9):1425-1436. https://doi.org/10.1002/smll.200800525.

[21] Katti K, Chanda N, Shukla R, Zambre A, Suibramanian T, Kulkarni RR, Kannan R, Katti KV. Nanotechnology from cumin phytochemicals: generation of biocompatible gold nanoparticles. International Journal of Nanotechnology: Biomedicine 2009; 1:B39-52. https://doi.org/10.1080/19430850902931599.

[22] Nune S, Chanda N, Shukla R, Katti K, Kulkarni RR, Thilakavathy S, Mekapothula S, Kannan R, Katti KV. Green nanotechnology from tea: phytochemicals in tea as building blocks for production of biocompatible gold nanoparticles. J Mater Chem 2009; 19:29122920. https://doi.org/10.1039/b822015h.

[23] Mathew S, Abraham TE. Studies on the antioxidant activities of cinnamon (Cinnamomumverum) bark extracts, through various in vitro models. Food Chem 2006; 94:520-528. https://doi.org/10.1016/j.foodchem.2004.11.043.

[24] Lopez P, Sanchez C, Batlle R, Nerin C. Vapor-phase activities of cinnamon, thyme, and oregano essential oils and key constituents against foodborne microorganisms. J Agric Food Chem 2007; 55:4348-4356. https://doi.org/10.1021/jf063295u.

[25] Shan B, Cai YZ, Brooks JD, Corke H. Antibacterial properties and major bioactive components of cinnamon stick (Cinnamomum burmannii): activity against foodborne pathogenic bacteria. J Agric

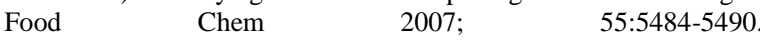
https://doi.org/10.1021/jf070424d.

[26] Giuliani P, Zuccarini M, Buccella S, Rossini M, D'Alimonte I, Ciccarelli R, Marzo M, Marzo A, Di Iorio P, Caciagli F. Development of a new HPLC method using fluorescence detection without derivatization for determining purine nucleoside phosphorylase activity in human plasma. J Chromatogr B Analyt Technol Biomed Life Sci 2016; https://doi.org/10.1016/j.jchromb.2015.12.012.

[27] Tsai YJ, Chen BH. Preparation of catechin extracts and nanoemulsions from green tea leaf waste and their inhibition effect on prostate cancer cell PC-3. Int J Nanomed 2016; 11:1907-1926. https://doi.org/10.2147/IJN.S103759.

[28] Yu Y, Hamza A, Zhang T, Gu M,Zou P, Newman B, Li Y, Gunatilaka AAL, Whitesell L, Zhan C-G, Sun D. Withaferin A Targets Heat Shock Protein 90 in Pancreatic Cancer Cells. BiochemPharmacol 2010; 79(4):542-551. https://doi.org/10.1016/j.bcp.2009.09.017.

[29] Liao B, Ying H, Yu C, Fan Z, Zhang W, Shi J, Ying H, Ravichandran $\mathrm{N}, \mathrm{Xu} \mathrm{Y}$, Yin J, Jiang $\mathrm{Y}$, Du Q. (-)Epigallocatechingallate(EGCG)-nanoethosomes as a transdermal delivery system for docetaxel to treat implanted human melanoma cell tumors in mice. Int $\mathrm{J}$ Pharm 2016; 512(1):22-31. https://doi.org/10.1016/j.ijpharm.2016.08.038.
[30] Capistrano R, Vangestel C, Wouters A, Dockx Y, Pauwels P, Stroobants S, Apers S, Lardon F, Pieters L, Staelens S. Efficacy screening of Gloriosa superba extracts in a murine pancreatic cancer model using ${ }^{18} \mathrm{~F}-\mathrm{FDG}$ PET/CT for monitoring treatment response. Cancer Biother Radiopharmaceut 2016; 31:99-109. https://doi.org/10.1089/cbr.2015.1954.

[31] Liu M, Dong J, Lin Z, Niu Y, Zhang X, Jiang H, Guo N, Li W, Wang $\mathrm{H}$, Chen $\mathrm{S}$. Rapid screening of transferrin-binders in the flowers of Bauhinia blakeana Dunn by on-line high-performance liquid chromatography-diode-array detector-electrospray ionization-ion-trap-time-of-flight-mass spectrometry-transferrinfluorescence detection system. J Chromatogr A 2016; 1450:17-28. https://doi.org/10.1016/j.chroma.2016.04.043.

[32] Borda Rodríguez M, AnduezaIriarte M. Evaluation of the effectiveness of an oil extract of rosehip in the prevention of epithelitis due to radiotherapy in patients with head and neck cancer. Rev Enferm 2016; 39(1):49-52. PMID: 26996043.

[33] Butterfield LH. Cancer vaccines. BMJ 2015; 350:h988. https://doi.org/10.1136/bmj.h988.

[34] George BP, Abrahamse H. A Review on Novel Breast Cancer Therapies: Photodynamic Therapy and Plant Derived Agent Induced Cell Death Mechanisms. Anticancer Agents Med Chem 2016; 16(7):793-801.

[35] Khoogar R, Kim BC, Morris J, Wargovich MJ. Chemoprevention in gastrointestinal physiology and disease. Targeting the progression of cancer with natural products: a focus on gastrointestinal cancer. Am J Physiol Gastrointest Liver Physiol 2016; 310(9):G629-G644. https://doi.org/10.1152/ajpgi.00201.2015. 